\title{
KLF11 promotes gastric cancer invasion and migration by increasing Twist 1 expression
}

\author{
Q. JI, Y. LI*, Q. ZHAO, L. Q. FAN, B. B. TAN, Z. D. ZHANG, X. F. ZHAO, Y. LIU, D. WANG, N. JIA \\ Department of General Surgery, The Fourth Affiliated Hospital of Hebei Medical University, Shijiazhuang, China \\ *Correspondence: li_yong_hbth@126.com
}

Received March 25, 2018 / Accepted July 11, 2018

\begin{abstract}
Gastric cancer (GC) is a leading cause of global cancer-related death. The incidence and mortality rates of gastric cancer in China are second and third ranked in all forms of malignant tumors. Krüppel-like factor11 (KLF11) is a member of the KLF family, and previous studies have shown it significantly influences epithelial ovarian, pancreatic and liver cancer proliferation, differentiation and apoptosis. However, the expression and some biological functions of KLF11 in GC are still unclear. We therefore collected and analyzed the mRNA and protein expressions of KLF11 in 59 paired gastric cancer tissues and matched healthy gastric tissue samples. We then investigated the KLF 11 biological functions and potential mechanisms in BGC823 and HGC27 gastric cancer cell lines. Analysis of KLF11 in gastric cancer specimens confirmed up-regulation compared to adjacent healthy gastric tissues, and similar results were evident in the GC cell lines. Ectopic expression of KLF11 was significantly associated with GC cell invasion and migration. KLF11 functions were most effective in Twist1 expression and knockdown, and also in KLF11 up-regulation which was accompanied by corresponding change in Twist1 expression; but these effects were inhibited when KLF11 was silenced by the small interfering RNA (siRNA). The relative Twist 1 promoter region activity increased gradually with increasing KLF11 plasma, and KLF11 therefore has a critical role in regulating gastric cancer migration and invasion by increasing Twistl expression. Finally, the results of this study should improve understanding of the KLF11 and EMT regulating network and KLF11's use as a potential therapeutic target in gastric cancer.
\end{abstract}

Key words: KLF11, gastric cancer, cell invasion, cell migration, Twist1

Gastric cancer is a very common malignant tumor [1]. According to statistics, there are about 1 million new cases and 800,000 people in the world die from GC every year [2]. In China, the incidence and mortality rates of gastric cancer occupy the second and third position in all forms of malignant tumors in both sexes [3]. Furthermore, the incidence rate of GC is still on the rise. Despite improved GC therapeutic strategies, the prognosis of advanced GC patients remains unsatisfactory; with the 5-year survival rate less than $30 \%$ [4]. This poor diagnosis rate is due to the atypical clinical symptoms of the GC patients and the low sensitivity of the markers. Therefore, finding novel sensitive markers and therapeutic targets is essential.

Epithelial-to-mesenchymal transition (EMT) is a hallmark of cancer and it attracts great attention because of its pivotal role in facilitating cancer cell invasion and metastasis $[5,6]$. Suppression of E-cadherin is the most important symbol of EMT, and this not only breaks cell-cell adhesions but also promotes cellular migration and invasion [6]. In addition to the above abilities, EMT also enables cancer cells to obtain the characteristics of stem cells, including selfrenewal and resistance to apoptosis $[7,8]$. Previous studies have shown that transcription factors have a most important role in EMT progression [9], and Snail and Twist are the two most commonly associated with EMT. Some studies have demonstrated that Snail and Twist restrain the expression of E-cadherin by combining with the $\mathrm{CDH} 1$ promoter and thus aid the EMT process [10-12]. However, EMT regulation is most complex because Twist1 also affects the EMT process by regulating Snail2 [13].

KLF is a highly conserved family of zinc finger transcription factors [14] associated with cellular proliferation, differentiation, migration, invasion, apoptosis, cardiovascular disease and metabolic disorders [15]. KLF11 is a member of this family and contains three $\mathrm{C}_{2} \mathrm{H}_{2}$-type zinc fingers, 2 acids and 2 regions rich in proline at the carboxyl and amino 
terminals [16]. Previous studies have shown that KLF11 has significant influence on proliferation, differentiation and apoptosis in epithelial ovarian, pancreatic and liver cancer [17-20]. While KLF11 promotes local invasion and distant migration in the EMT process in hepatocellular carcinoma [21], its biological functions and relationship with EMT in gastric cancer are not clarified.

\section{Patients and methods}

Clinical samples. A total of 59 paired gastric cancer tissues and the matched healthy gastric tissue samples from at least $5 \mathrm{~cm}$ from the tumor edge were frozen in liquid nitrogen. All samples were obtained from the Fourth Affiliated Hospital of Hebei Medical University. No patients had received chemotherapy or radiotherapy before operation.

Cell lines and cell culture. Human gastric cancer cell lines MKN28, MGC803, SGC7901, MKN45, BGC823, HGC27 and GES1 were obtained from the Committee of Type Culture Collection of the Chinese Academy of Sciences (Shanghai, China) and cultured in RPMI-1640 (Gibco, USA) supplemented with $10 \%$ fetal bovine serum(FBS) (Excell, USA) and $1 \%$ streptomycin/penicillin in a humidified atmosphere containing $5 \% \mathrm{CO}_{2}$ at $37^{\circ} \mathrm{C}$ (Thermal, USA). GES1 is one of the normal gastric epithelial cell lines.

RNA extraction, reverse transcription and qRT-PCR. Total RNA was extracted from tissue samples or cells with TRNzol universal reagent (TIANGEN, China). After measuring the concentration, $3 \mu \mathrm{g}$ of the total RNA was reverse-transcribed using the A5001 GoScript Reverse Transcription System (Promega, USA). Real time PCR reactions were conducted by A6001 GoTaq(R) qRTPCR Master Mix (Promega, USA) on the ABI PRISM 7500 sequence detection system (Applied Biosystems). All reactions were set with three sub-holes. The GAPDH was used as the endogenous controls and the relative expression levels of KLF11were calculated using the $2^{-\Delta \Delta C T}$ equation. The primer of KLF11 was designed by and purchased from Sangon Biotech (Shanghai). The primer sequences were:

KLF11 F: 5'-GGGATGTCACCACCACTGT-3', R:5'-GGCTCTGAGGAGGAGTTATGC-3'.

GAPDH F: 5'-AATCCCATCACCATCTTCCAG-3', R: 5'-CCTTCTCCATGGTGGTGAAGAC-3'.

Protein extraction and western blot. Total proteins were extracted from clinical samples and all cell lines by RIPA lysis buffer (Solarbio, China) and $1 \times$ protease inhibitor cocktail (Roche, Mannheim, Germany). Bicinchoninic acid (BCA) protein assay (Thermal, USA) was used to measure the concentrations of proteins according to the manufacturer's instructions. The proteins were separated by $10-12 \%$ SDS-PAGE and transferred onto polyvinylidene fluoride (PVDF) membranes for $2 \mathrm{~h}$ (Millipore, Billerica, MA). The membranes were blocked in 5\% fat-free milk for $1 \mathrm{~h}$ at room temperature and incubated with primary antibodies at $4{ }^{\circ} \mathrm{C}$ overnight. The next day, the membrane was incubated with the secondary antibody for $1 \mathrm{~h}$ at room temperature and in the dark. Bands on the membrane were detected by Odyssey system (LI-COR Biosciences, USA) and $\beta$-actin was the endogenous control. all experiments were in triplicate.

Cell transfection, $5 \times 10^{5}$ BGC823 or HGC27cells were seeded into a 6 -well plate per well for $24 \mathrm{~h}$ prior to transfection and the 6-well plate was cultured in humidified atmosphere with $2 \mathrm{ml}$ RPMI-1640 overnight. When the cells grew to $70-80 \%$ confluence, the KLF11-siRNA or pcDNAKLF11 was transfected into cells with Lipofectamine ${ }^{\mathrm{Tm}}$ 2000 (Invitrogen, USA) according to the manufacturer's instructions. The control group was set in each group. Then qRT-PCR and Western blot confirmed transfection efficiency. After $24 \mathrm{~h}$ or $48 \mathrm{~h}$ of transfection, cells were collected for following experiments. siRNAs and pcDNA plasmids were designed by and purchased from Ribo Bio (Guangzhou, China).

Wound healing assay. Cells were seeded in 6-well plates $\left(5 \times 10^{5}\right.$ cells/well). After transfection, when the cells confluence surpassed $80 \%$, the cell layer was wounded gently by

Table 1. Relationships between KLF11 expression and clinical pathological data.

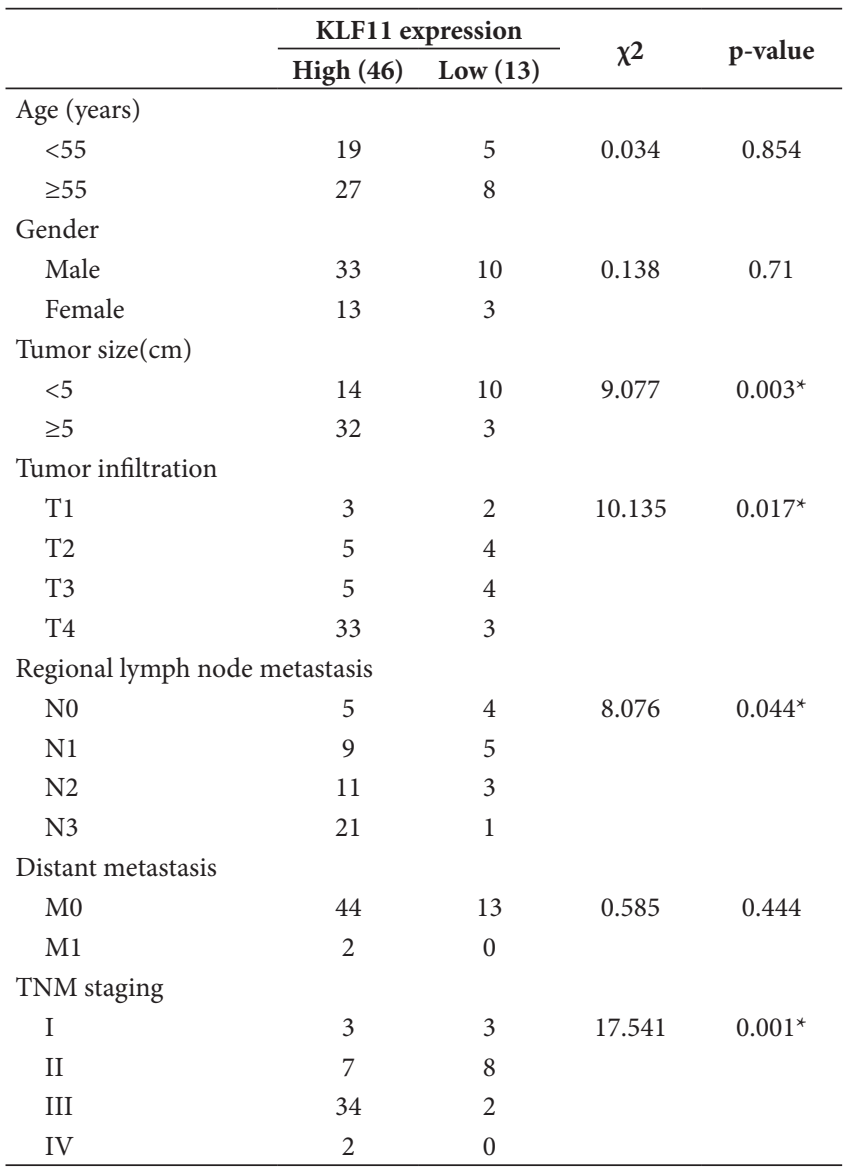

$\mathrm{T} 1$ includes T1a and T1b, T4 includes T4a and T4b. N3 includes N3a and N3b. TNM staging I includes Ia and Ib, II includes IIa and IIb, III includes IIIa, IIIb and IIIc. ${ }^{*} \mathrm{p}<0.05$ 
a $0.2 \mathrm{ml}$ micropipette tip across the diameter of the well. Then, after washing twice with $1 \times \mathrm{PBS}$, cells were cultured with serum-free medium containing $1 \mathrm{mM}$ mitomycin which was used to inhibit cell division. Pictures were captured by inverted microscope at different time points after the scratching.

Transwell invasion assay. The invasion of GC cell lines was measured by 24-well Transwell chambers (Corning Costar, Cambridge, MA, USA). The upper chambers were pretreated with a thin layer of Matrigel (BD Biosciences, USA). $1 \times 10^{5}$ cells were re-suspended in serum-free medium and seeded in the upper chambers. Meanwhile, in the lower chamber, $600 \mu \mathrm{l}$ RPMI-1640 with 10\% FBS was supplemented and acted as the attractant. After incubation of $20 \mathrm{~h}$ at $37^{\circ} \mathrm{C}$, cells on the upper sides were wiped by a cotton swab, and the cells on the lower portion were stained with $2 \%$ crystal violet for $10 \mathrm{~min}$. The numbers of stained cells in six random fields were counted under the inverted microscope and used for analysis.

Luciferase reporter assay. We established a luciferase reporter gene plasmid of Twistl with the $2 \mathrm{~kb}$ sequence upstream of the promoter region. When the cells grew to $70 \%$ confluence, pGL3-Twist1-luc was co-transfected into cells along with different dose pcDNA-KLF11 $(0.1,0.2,0.4$, and $0.8 \mu \mathrm{g}$ ) and the pRL-TK was used as the reference. At $48 \mathrm{~h}$ after transfection, the Dual-Luciferase ${ }^{\otimes}$ Reporter Assay System (Promega, Madison, WI) measured the luciferase activity and this is presented as mean $\pm \mathrm{SD}$. The above experiments were in triplicate.

Statistical analysis. The statistical software SPSS21.0 processed experimental data. All quantitative data is presented as the mean \pm SD. Comparisons between different groups was by one-way analysis of variance and test. Chi-square analysis analyzed categorical variables and two tailed $\mathrm{p}$-values $<0.05$ were statistically significant.

\section{Results}

KLF11 is up-regulated in GC tissues and various GC cell lines. The expressions of KLF11 were detected via qRT-PCR and WB in 59 paired gastric cancer tissues and the adjacent healthy gastric tissue samples. KLF11 was up-regulated in 46 GC tissues compared to matched healthy gastric tissues (Figures 1A, B). From HGC27, BGE823, MKN45, SGC7901, MGC803, MKN28 and GES1 groups, HGC27 had the highest KLF11expression, followed by GC cell lines BGC823,
A

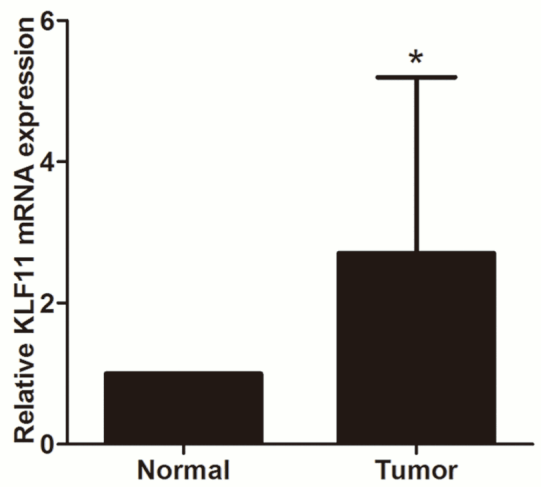

B

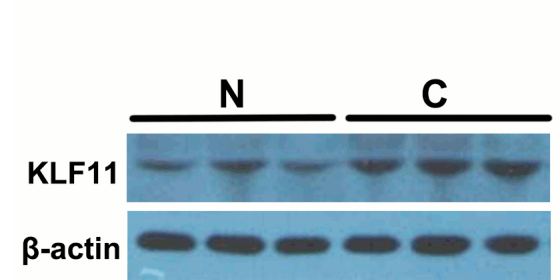

C

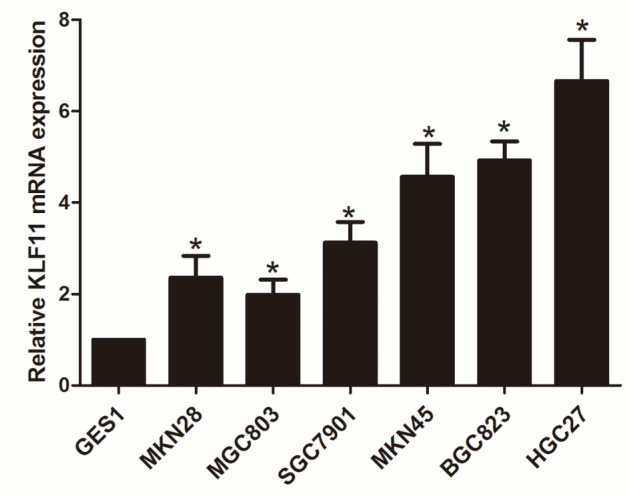

D

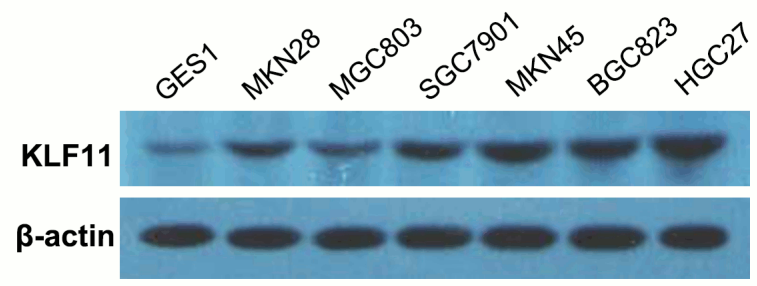

Figure 1. KLF11 expression in GC clinical tissues and various cell lines. A) The mRNA expression levels of KLF11 in 59 paired gastric cancer tissues were assessed by qRT-PCR. B) The protein expressions of KLF11 in GC tissues (C) and the paired para-carcinoma tissues (N) were shown by WB. C) The mRNA and protein expression levels of KLF11 in various cell lines were tested by $q R T-P C R$ and $W B .{ }^{*} p<0.05$ 
A
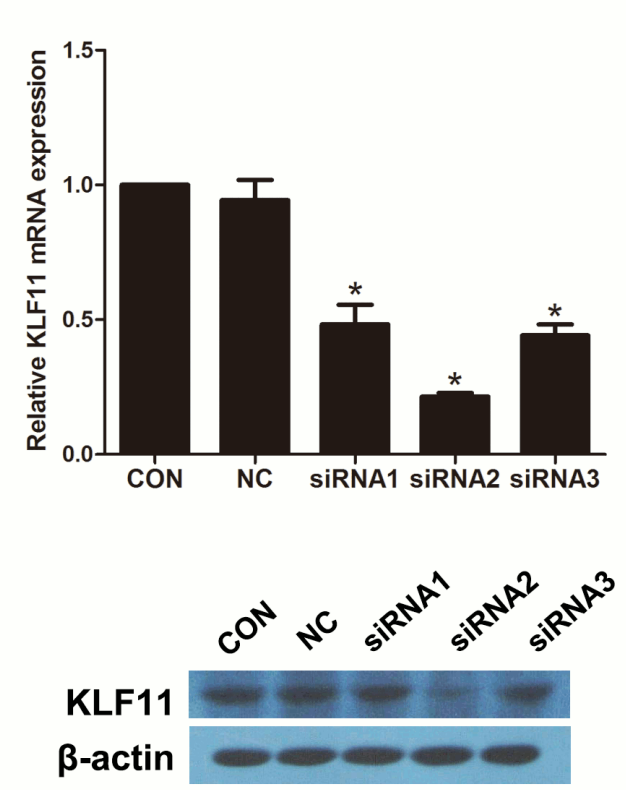

C

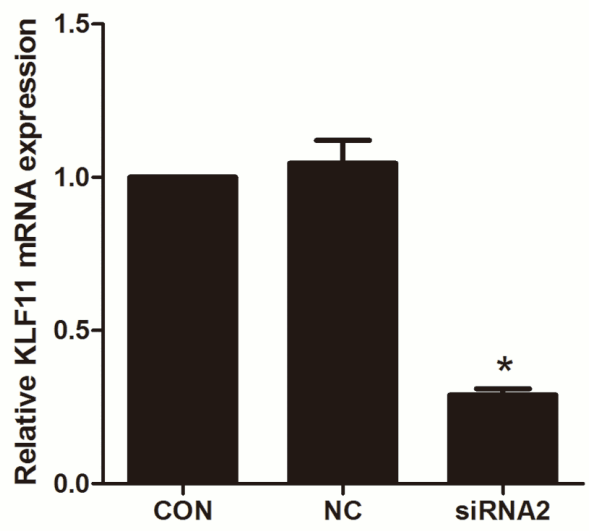

B

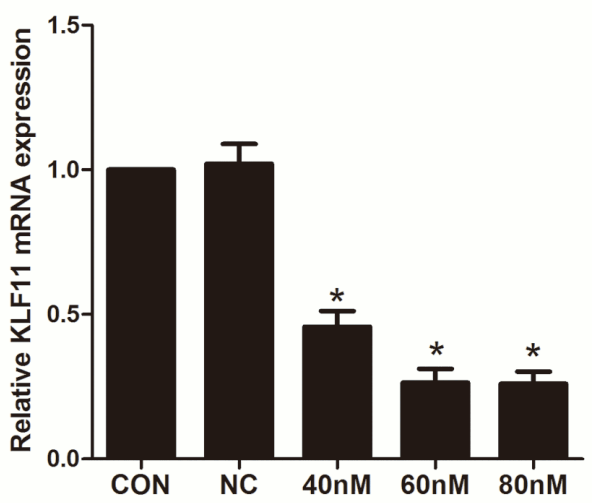

CON NC 40nM 60nM 80nM

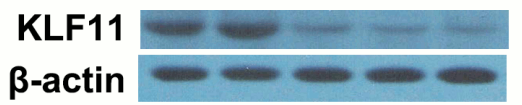

KLF11

$\beta$-actin

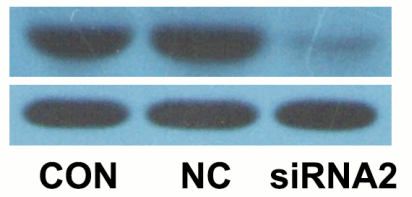

Figure 2. Knockdown of KLF11 in BGC823 cells. A) qRT-PCR and WB assessed the BGC823 cell mRNA and protein levels. These cells were transfected by KLF11-siRNA1, KLF11-siRNA2, KLF11-siRNA3 and NC-siRNA at the concentration of $60 \mathrm{nM}$. B) The BGC823 cell was transfected by different doses of KLF11-siRNA2 at $40 \mathrm{nM}, 60 \mathrm{nM}$, and $80 \mathrm{nM}$, and the NC group with $60 \mathrm{nM}$ concentration. C) The mRNA and protein levels of KLF11 were measured when KLF11-siRNA2 was transfected into the HGC27 cell. ${ }^{\star} \mathrm{p}<0.05$

MKN45, SGC7901, MGC803, MKN28; and the least was in the GES1 cell line (Figures 1C, D).

The relationship between KLF11 expression and clinical pathological characteristics. We found that KLF11 was up-regulated in gastric cancer tissues compared to matched adjacent gastric tissues. We analyzed the relationship between KLF11 expression and the clinical-pathological characteristics. The results showed that higher KLF11 expression was associated with tumor size and infiltration, regional lymph node metastasis and TNM staging (Table 1).

KLF11 is down-regulated in KLF11-siRNA cell line. The qRT-PCR and Western blot assays demonstrated that the mRNA and protein levels of KLF11 were stably reduced when the KLF11-siRNA2 was transfected in BGC823 cells. KLF11 remained at the same level in the NC-siRNA and Control groups (Figure 2A). We found dose-dependent effects of BGC823 with KLF11-siRNA2 transfected at concentrations ranging from 40 to $80 \mathrm{nM}$ (Figure 2B). The mRNA and protein levels of KLF11 were also reduced when KLF11siRNA2 was transfected into HGC27 cells (Figure 2C).

Down-regulation of KLF11 inhibits cell invasion and migration. To investigate the biological influences of KLF11, we conducted the wound-healing and Transwell invasion experiments. This assessed the migration and invasion of BGC823 and HGC27 cells which were transfected with NC-siRNA or KLF11-siRNA. As shown in Figure 3A, down-regulation of KLF11 notably inhibited the abilities of migration compared to the negative control 

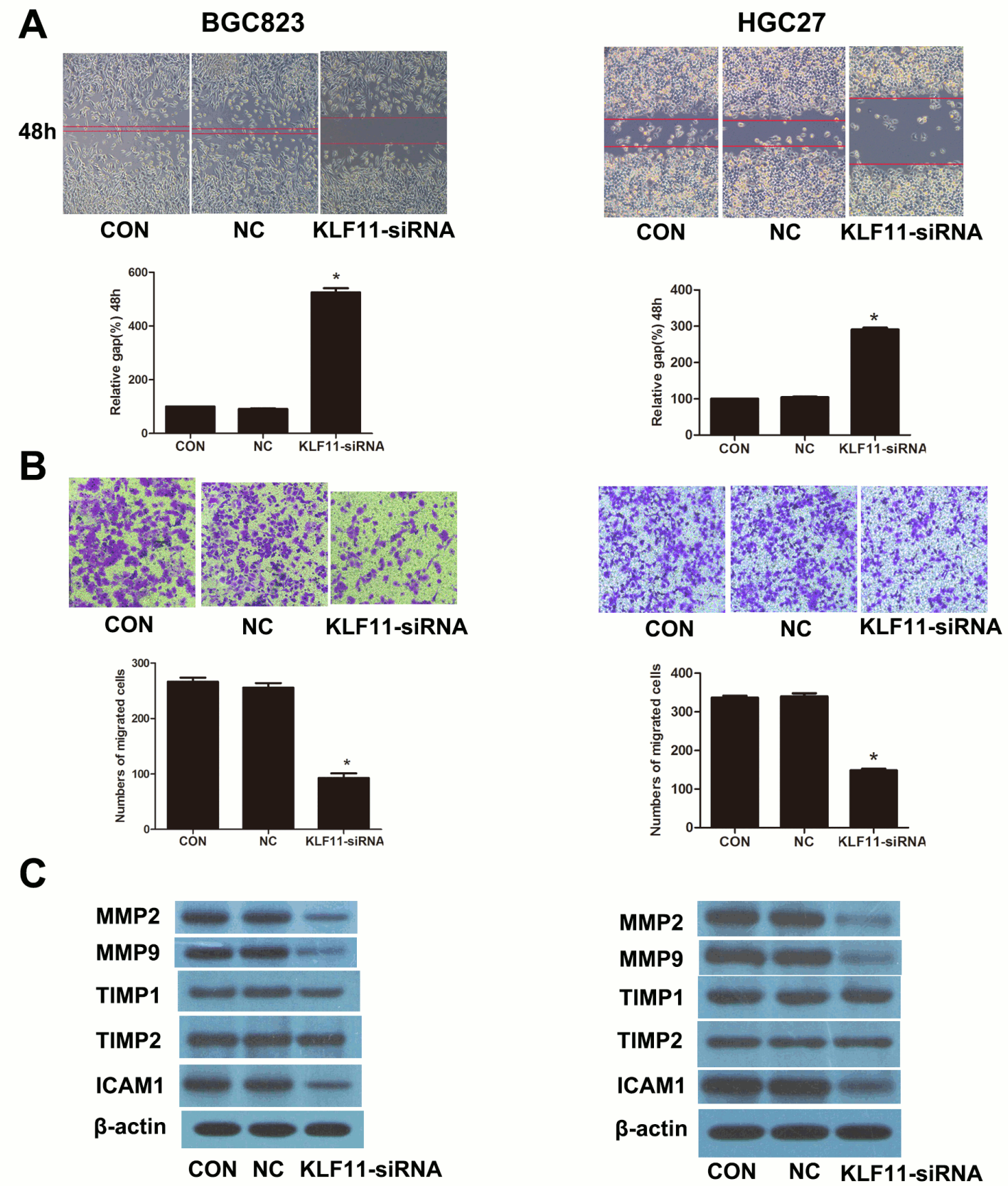

Figure 3. Down-regulation of KLF11 inhibits cell migration and invasion. A) Wound healing assay, B) Transwell invasion assay and C) The changes in MMP2, MMP9, TIMP1, TIMP2 and ICAM1 were tested in BGC823 and HGC27 cell lines by qRT-PCR and WB. ${ }^{\star}$ p $<0.05$

group. The numbers of migrated cells were observably reduced in the group of KLF11-siRNA (Figure 3B). We also detected the expressions of MMP2, MMP9, TIMP1, TIMP2 and ICAM1 proteins to explore potential mechanisms, and results revealed that the expression levels of protein MMP2, MMP9 and ICAM1 were obviously reduced in the group of KLF11-siRNA, while TIMP1 and TIMP2 remained at the same level (Figure 3C).
KLF11 may regulate Twist1 expression to induce EMT. We observed change in cell migration and invasion ability. Results indicated that KLF11 participates in the progress of EMT. We then detected the expressions of protein markers of EMT in BGC823 and HGC27 cell lines to confirm these observations. Figures $4 \mathrm{~A}$ and $\mathrm{B}$ show that the E-cadherin epithelial cell marker protein was up-regulated and detected by qRT-PCR and WB assays in the KLF11-siRNA group and 
A
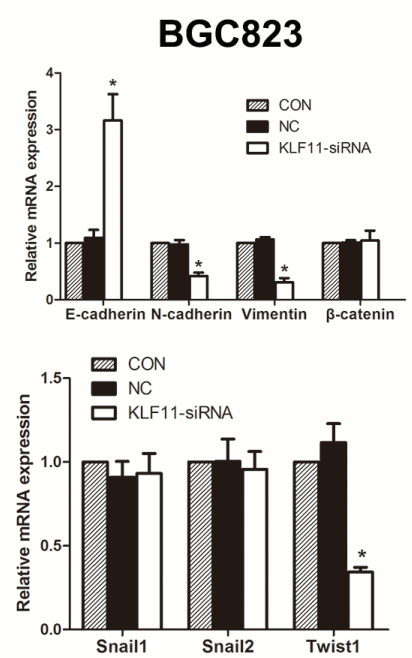

\section{E-cadherin}

$\mathrm{N}$-cadherin

Vimentin

$\beta$-catenin

Snail1

Snail2

Twist1

$\beta$-actin
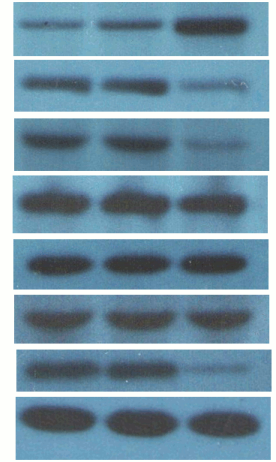

CON NC KLF11-siRNA
B

HGC27
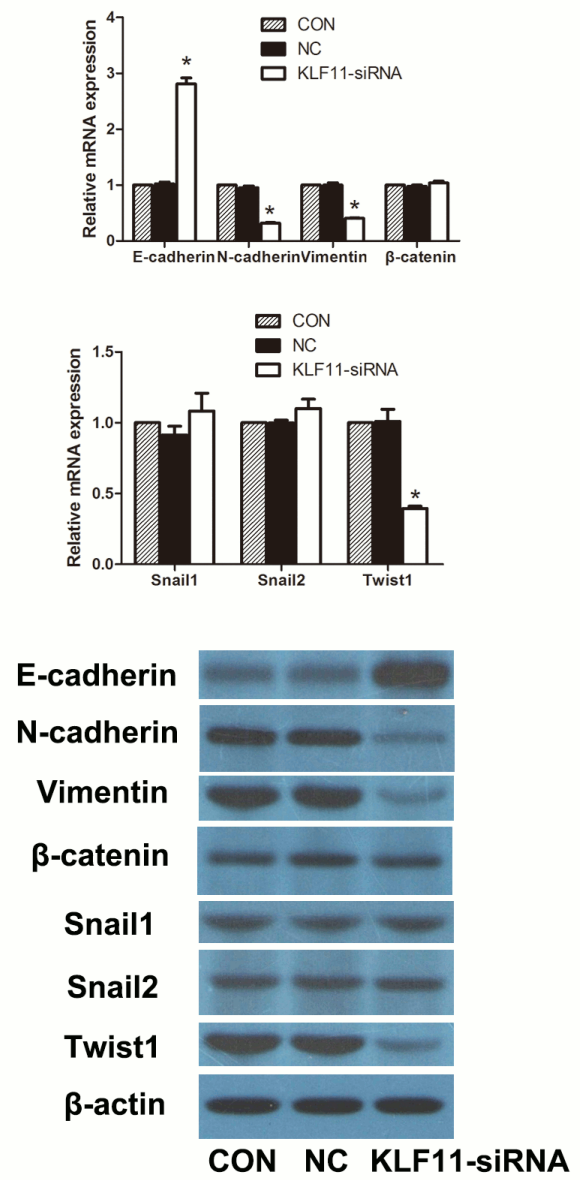

C

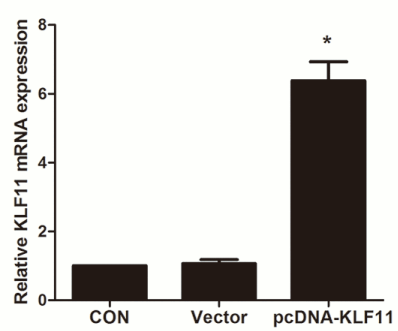

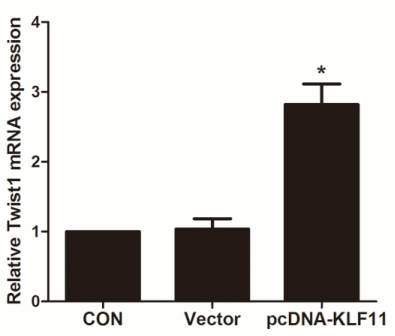

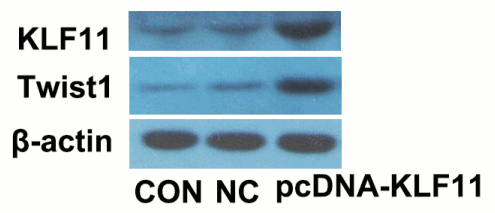

Figure 4. KLF11 may regulate Twist1 expression to induce EMT. The specific biomarkers of EMT including E-cadherin, N-cadherin, Vimentin and $\beta$-catenin were assessed by qRT-PCR and WB with BGC823 (A) and HGC27 (B) cell lines. Snail1, Snail2 and Twist1 were also checked by qRT-PCR and WB in the different groups. C) Following transfection with pcDNA-KLF11 or Vector, the BGC823 cells were assessed by $q R T-P C R$ and WB assays to determine Twist 1 expression. ${ }^{*} \mathbf{p}<0.05$

the opposite expression of $\mathrm{N}$-cadherin and Vimentin mesenchymal cell marker proteins were noted. There was no significant change in the expression of $\beta$-catenin. Snail and Twist were the two most significant transcription factors inducing EMT proceeding. To investigate the potential mechanism of KLF11-reduced EMT, we assessed the expressions of Snail1, Snail2 and Twist1 in BGC823 and HGC27 cell lines. The expression levels in mRNA and protein of Twist1 were reduced and Snaill and Snail 2 remained at the same levels in the KLF11-siRNA group. In order to further confirm the KLF11-induced change of Twist1, we up-regulated the expression of KLF11 through transfecting pcDNA-KLF11; with corresponding improvement in Twistl detected in the BGC823 cell line (Figure 4C).

KLF11 induces EMT through binding to the promoter region of Twist1. In order to further verify whether KLF11 induces EMT through binding to the promoter region of Twist1, we conducted Luciferase reporter assay in the 
A

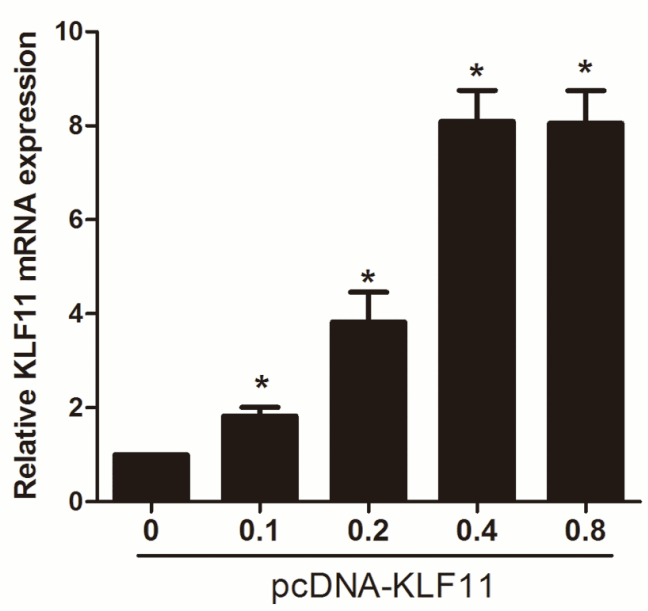

C

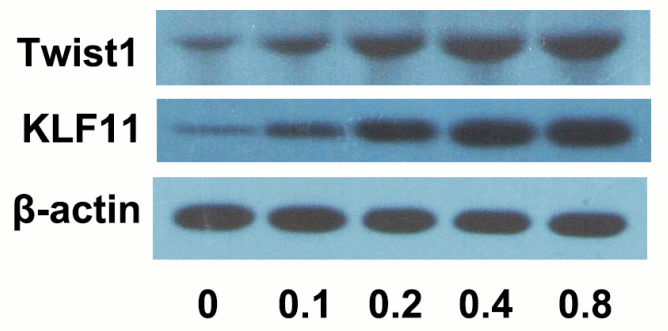

B
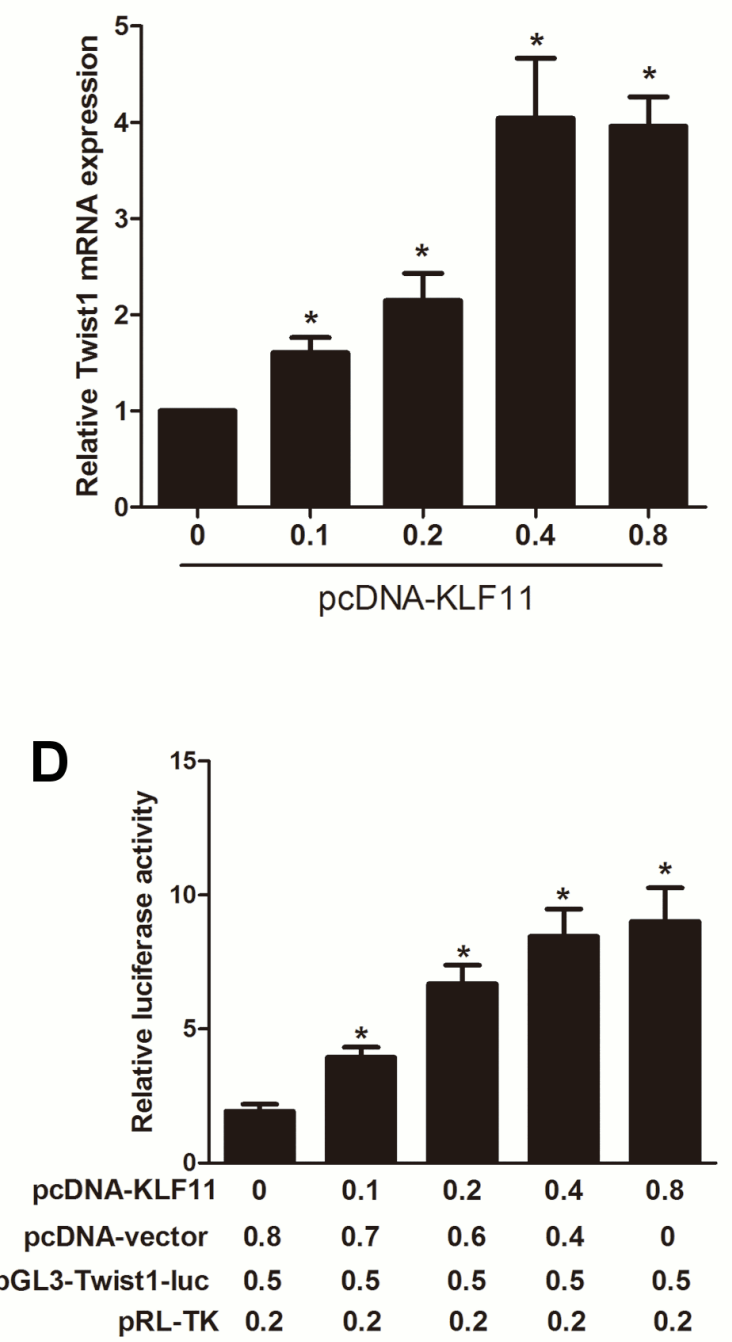

Figure 5. KLF11 induces EMT by binding to the Twist1 promoter region. $(\mathrm{A}, \mathrm{B}, \mathrm{C})$ the corresponding changes in Twist1 $\mathrm{mRNA}$ and protein were detected by QRT-PCR and WB according to the increasing amounts of KLF11 plasmid $(0,0.1,0.2,0.4,0.8 \mu$ g). D) The luciferase activities of the Twist1 promoter region were tested by Luciferase reporter assay with the different doses of pcDNA-KLF11 $(0,0.1,0.2,0.4,0.8 \mu \mathrm{g}) .{ }^{*} \mathrm{p}<0.05$

BGC823 cell line. The results show that as the amounts of KLF11 plasmid increased $(0,0.1,0.2,0.4,0.8 \mu \mathrm{g})$, activity of the Twist 1 promoter region was gradually enhanced (Figure 5D). Corresponding changes in Twist1mRNA and protein were detected by qRT-PCR and WB (Figures $5 \mathrm{~A}-\mathrm{C}$ ).

\section{Discussion}

Gastric cancer is one of the most common malignant tumors in the world. Although the mortality rate of GC appears to have decreased in the last decades, it still ranks third in all forms of malignant tumors [3]. Due to the lack of obvious symptoms and sensitive markers, many GC patients missed surgery until diagnosis. Previous studies showed that patients diagnosed in advanced stages had only $20-30 \%$ survival; and tumor invasion and metastasis were the main causes of cancer-related death [22]. It is therefore imperative to find new markers and therapeutic targets in gastric cancer.

KLF is a highly conserved family of zinc finger transcription factors associated with cellular proliferation, differentiation, migration, invasion, apoptosis, cardiovascular disease and metabolic disorders. KLF aids recruiting transcriptional regulatory proteins, including transcriptional co-activators 
and co-repressors $[14,15]$. In previous studies, KLF11 supported TGF- $\beta$ signaling by terminating the smad7 loop and activating smad3; thus exerting anti-proliferative and pro-apoptotic functions in epithelial ovarian, pancreatic and liver cancer cells [17-20]. In the process of TGF- $\beta$ induced EMT, KLF11 significantly promoted hepatocellular carcinoma local invasion and distant metastasis by binding to the Smad7 promoter and suppressing transcription of Smad7 or directly up-regulating Smad2/3 expression [21, 23]. However, there are no reports on relationship between KLF11 and the EMT process in GC.

This is the first known study to establish increased expression levels of mRNA and protein of KLF11 in GC tissues and cell lines. Ectopic expression of KLF11 in gastric cancer cell notably promoted cell invasion and migration in vitro, and silencing KLF11 restrained these abilities.

The MMP-2 and MMP-9 members of the matrix metalloproteinases (MMP) family aid cancer cell spread by breaking down the extracellular matrix, and this is important in the EMT process $[24,25]$. Our study of migratory and invasive proteins established that MMP-2, MMP-9 and ICAM1 [26] are reduced when KLF11 is silenced by siRNA, and results revealed that KLF11 partly mediates migration and invasion by regulating MMP-2, MMP-9 and ICAM1.

EMT is the process of transforming epithelial cells to mesenchymal cells under special physiological and pathological conditions. This is especially characterized by reduction in E-cadherin and over-expression of $\mathrm{N}$-cadherin and Vimentin $[27,28]$. Our results agreed with the above changes of EMT-related markers, and the combined results suggest that KLF11 has a crucial role in the EMT process.

It is known that the EMT process is affected by a complex regulating network, including various signaling pathways and transcription factors, and some non-coding RNAs and long non-coding RNAs also participate in EMT regulation [29]. Snail and Twist have been the most common transcription factors studied because they repress E-cadherin protein function [10, 30]. Recent research shows that MMPs promote transcription factors expression, including Snail, Twist and consequent EMT function in mammary epithelial cells. Snail is an established suppressor of E-cadherin and regulates MMP expression; a key factor in the EMT process $[31,32]$.

Other studies have shown that Twist1 is highly expressed in glioma and there is also up-regulated MMP2 expression in many tumor types. They also determined that Twist1 interacts directly with the MMP2 promoter to regulate MMP2 expression [33]. Twist1 has been proven to induce EMT in gastric cancer cells by reducing E-cadherin expression and increasing that of N-cadherin and Vimentin [34]. Herein, we reveal that Twist 1 changed according to the expression of KLF11; not that of Snail 1 or Snail 2. Further research then confirmed that Twist1 is a down-stream target of KLF11, so that KLF11 then enhanced GC invasion and migration via binding to the TWIST 1 promoter region.
In conclusion, our study established that KLF11 is up-regulated in GC, and that it promotes the EMT process by increasing Twistl expression. This is novel regulation of EMT, and our combined results may therefore improve understanding of EMT network regulation and KLF11 may be used as a therapeutic target in gastric cancer in the future.

\section{References}

[1] FERLAY J, STELIAROVA-FOUCHER E, LORTET-TIEULENT J, ROSSO S, COEBERGH JW et al. Cancer incidence and mortality patterns in Europe: estimates for 40 countries in 2012. Eur J Cancer 2013; 49: 1374-1403. https://doi. org/10.1016/j.ejca.2012.12.027

[2] BEEHARRY MK, LIU WT, YAN M, ZHU ZG. New blood markers detection technology: A leap in the diagnosis of gastric cancer. World J Gastroenterol 2016; 22: 1202-1212. https://doi.org/10.3748/wjg.v22.i3.1202

[3] CHEN W, ZHENG R, ZHANG S, ZENG H, XIA C et al. Cancer incidence and mortality in China, 2013. Cancer Lett 2017; 401: 63-71. https://doi.org/10.1016/j.canlet.2017.04.024

[4] SIEGEL RL, FEDEWA SA, MILLER KD, GODING-SAUER A, PINHEIRO PS et al. Cancer statistics for Hispanics/Latinos, 2015. CA Cancer J Clin 2015; 65: 457-480. https://doi. org/10.3322/caac. 21314

[5] NIETO MA. The ins and outs of the epithelial to mesenchymal transition in health and disease. Annu Rev Cell Dev Biol 2011; 27: 347-376. https://doi.org/10.1146/annurevcellbio-092910-154036

[6] HANAHAN D, WEINBERG RA. Hallmarks of cancer: the next generation. Cell 2011; 144: 646-674. https://doi. org/10.1016/j.cell.2011.02.013

[7] MANI SA, GUO W, LIAO MJ, EATON EN, AYYANAN A et al. The epithelial-mesenchymal transition generates cells with properties of stem cells. Cell 2008; 133: 704-715. https://doi.org/10.1016/j.cell.2008.03.027

[8] MEDEMA JP. Cancer stem cells: the challenges ahead. Nat Cell Biol 2013; 15: 338-344. https://doi.org/10.1038/ncb2717

[9] ZHENG H, KANG Y. Multilayer control of the EMT master regulators. Oncogene 2014; 33: 1755-1763. https://doi. org/10.1038/onc.2013.128

[10] WANG Y, SHI J, CHAI K, YING X, ZHOU BP. The Role of Snail in EMT and Tumorigenesis. Curr Cancer Drug Targets 2013; 13: 963-972.

[11] QIN Q, XU Y, HE T, QIN C, XU J. Normal and diseaserelated biological functions of Twist1 and underlying molecular mechanisms. Cell Res 2012; 22: 90-106. https://doi. org/10.1038/cr.2011.144

[12] FU J, QIN L, HE T, QIN J, HONG J et al. The TWIST/Mi2/ NuRD protein complex and its essential role in cancer metastasis. Cell Res 2011; 21: 275-289. https://doi.org/10.1038/ cr.2010.118

[13] MAO Y, ZHANG N, XU J, DING Z, ZONG R et al. Significance of heterogeneous Twist2 expression in human breast cancers. PLoS One 2012; 7: e48178. https://doi.org/10.1371/ journal.pone.0048178 
[14] KACZYNSKI J, COOK T, URRUTIA R. Sp1- and Kruppellike transcription factors. Genome Biol 2003; 4: 206.

[15] BUREAU C, HANOUN N, TORRISANI J, VINEL JP, BUSCAIL L et al. Expression and Function of Kruppel LikeFactors (KLF) in Carcinogenesis. Curr Genomics 2009; 10: 353-360. https://doi.org/10.2174/138920209788921010

[16] COOK T, GEBELEIN B, MESA K, MLADEK A, URRUTIA R. Molecular cloning and characterization of TIEG2 reveals a new subfamily of transforming growth factor-beta-inducible Sp1-like zinc finger-encoding genes involved in the regulation of cell growth. J Biol Chem 1998; 273: 25929-25936.

[17] WANG G, LI X, TIAN W, WANG Y, WU D et al. Promoter DNA methylation is associated with KLF11 expression in epithelial ovarian cancer. Genes Chromosomes Cancer 2015; 54: 453-462. https://doi.org/10.1002/gcc.22257

[18] ELLENRIEDER V, BUCK A, HARTH A, JUNGERT K, BUCHHOLZ $M$ et al. KLF11 mediates a critical mechanism in TGF-beta signaling that is inactivated by Erk-MAPK in pancreatic cancer cells. Gastroenterology 2004; 127: 607-620.

[19] BUCK A, BUCHHOLZ M, WAGNER M, ADLER G, GRESS $\mathrm{T}$ et al. The tumor suppressor KLF11 mediates a novel mechanism in transforming growth factor beta-induced growth inhibition that is inactivated in pancreatic cancer. Mol Cancer Res 2006; 4: 861-872. https://doi.org/10.1158/1541-7786. MCR-06-0081

[20] JUNG CJ, IYENGAR S, BLAHNIK KR, JIANG JX, TAHIMIC C et al. Human ESC self-renewal promoting microRNAs induce epithelial-mesenchymal transition in hepatocytes by controlling the PTEN and TGFbeta tumor suppressor signaling pathways. Mol Cancer Res 2012; 10: 979-991. https://doi. org/10.1158/1541-7786.MCR-11-0421

[21] HUJIE G, ZHOU SH, ZHANG H, QU J, XIONG XW et al. MicroRNA-10b regulates epithelial-mesenchymal transition by modulating KLF4/KLF11/Smads in hepatocellular carcinoma. Cancer Cell Int 2018; 18: 10. https://doi.org/10.1186/ s12935-018-0508-0

[22] LI ZX, KAMINISHI M. A comparison of gastric cancer between Japan and China. Gastric Cancer 2009; 12: 52-53. https://doi.org/10.1007/s10120-008-0495-2

[23] TU X, ZHENG X, LI H, CAO Z, CHANG H et al. MicroRNA-30 Protects Against Carbon Tetrachloride-induced Liver Fibrosis by Attenuating Transforming Growth Factor Beta Signaling in Hepatic Stellate Cells. Toxicol Sci 2015; 146: 157-169. https://doi.org/10.1093/toxsci/kfv081
[24] EGEBLAD M, WERB Z. New functions for the matrix metalloproteinases in cancer progression. Nat Rev Cancer 2002; 2: 161-174. https://doi.org/10.1038/nrc745

[25] SHAY G, LYNCH CC, FINGLETON B. Moving targets: Emerging roles for MMPs in cancer progression and metastasis. Matrix Biol 2015; 44-46: 200-206. https://doi. org/10.1016/j.matbio.2015.01.019

[26] PIETRUCZUK M, PIETRUCZUK A, PANCEWICZ S, HERMANOWSKA-SZPAKOWICZ T. [ICAM-1: structure, biological role and clinical significance]. Pol Merkur Lekarski 2004; 17: 507-511.

[27] ZAVADIL J, HALEY J, KALLURI R, MUTHUSWAMY SK, THOMPSON E. Epithelial-mesenchymal transition. Cancer Res 2008; 68: 9574-9577. https://doi.org/10.1158/0008-5472. CAN-08-2316

[28] SCANLON CS, VAN TUBERGEN EA, INGLEHART RC, D'SILVA NJ. Biomarkers of epithelial-mesenchymal transition in squamous cell carcinoma. J Dent Res 2013; 92: 114121. https://doi.org/10.1177/0022034512467352

[29] CEPPI P, PETER ME. MicroRNAs regulate both epithelialto-mesenchymal transition and cancer stem cells. Oncogene 2014; 33: 269-278. https://doi.org/10.1038/onc.2013.55

[30] YANG J, MANI SA, DONAHER JL, RAMASWAMY S, ITZYKSON RA et al. Twist, a master regulator of morphogenesis, plays an essential role in tumor metastasis. Cell 2004; 117: 927-939. https://doi.org/10.1016/j.cell.2004.06.006

[31] LIN C, TSAI P, KANDASWAMI C, LEE P, HUANG C et al. Matrix metalloproteinase- 9 cooperates with transcription factor Snail to induce epithelial-mesenchymal transition. Cancer Sci 2011; 102: 815-827. https://doi.org/10.1111/ j.1349-7006.2011.01861.x

[32] PRZYBYLO J, RADISKY D. Matrix metalloproteinase-induced epithelial-mesenchymal transition: tumor progression at Snail's pace. Int J Biochem Cell Biol 2007; 39: 1082-1088. https://doi.org/10.1016/j.biocel.2007.03.002

[33] RAHME GJ, ISRAEL MA. Id4 suppresses MMP2-mediated invasion of glioblastoma-derived cells by direct inactivation of Twist1 function. Oncogene 2015; 34: 53-62. https://doi. org/10.1038/onc.2013.531

[34] LIU AN, ZHU ZH, CHANG SJ, HANG XS. Twist expression associated with the epithelial-mesenchymal transition in gastric cancer. Mol Cell Biochem 2012; 367: 195-203. https://doi.org/10.1007/s11010-012-1333-8 